\title{
Article \\ An Eye-Tracking Study on the Effect of Different Signalized Intersection Typologies on Pedestrian Performance
}

\author{
Chiara Gruden ${ }^{1}$ D, Irena Ištoka Otković ${ }^{2}$ ad and Matjaž Šraml ${ }^{1, *(D)}$ \\ 1 Faculty of Civil Engineering, Transportation Engineering and Architecture, University of Maribor, \\ Smetanova Ulica 17, 2000 Maribor, Slovenia; chiara.gruden1@um.si \\ 2 Faculty of Civil Engineering and Architecture Osijek, Josip Juraj Strossmayer University of Osijek, \\ Vladimira Preloga 3, 31000 Osijek, Croatia; iirena@gfos.hr \\ * Correspondence: matjaz.sraml@um.si; Tel.: +386-2-22-94-371
}

check for updates

Citation: Gruden, C.; Ištoka Otković, I.; Šraml, M. An Eye-Tracking Study on the Effect of Different Signalized Intersection Typologies on Pedestrian Performance. Sustainability 2022, 14, 2112. https://doi.org/10.3390/ su14042112

Academic Editor: Gabriella Mazzulla

Received: 14 January 2022

Accepted: 10 February 2022

Published: 12 February 2022

Publisher's Note: MDPI stays neutral with regard to jurisdictional claims in published maps and institutional affiliations.

Copyright: (c) 2022 by the authors. Licensee MDPI, Basel, Switzerland. This article is an open access article distributed under the terms and conditions of the Creative Commons Attribution (CC BY) license (https:/ / creativecommons.org/licenses/by/ $4.0 /)$.

\begin{abstract}
Pedestrian safety is a well-known issue, such that many road safety associations emphasize measures to improve this aspect. One of the main conflict points is pedestrian crossings, where motorized and non-motorized traffic flows directly interact and where pedestrian attention and reaction are two elements that can strongly influence their safety. Nowadays, these aspects are often deviated by the use of smartphones to surf the Internet or social media. The aim of the present study is to find out (1) whether and how intersection typology affects pedestrian behavior, both in terms of attention and crossing performance, and (2) whether and how gaze and behavioral characteristics are affected by smartphone use and social media browsing. To achieve this goal, eye-tracking technology was used to obtain qualitative and quantitative information on the number of fixations, their duration, and reaction times of pedestrians. Additionally, from the eye-tracking videos, it was possible to derive pedestrian waiting times, crossing times, and speeds. Statistical tests were conducted to determine if there is a significant difference in pedestrian behavior at the three different types of intersections and in their behavior when using or not using their device. Results confirm the initial hypotheses and quantify the difference in pedestrian gaze behavior and crossing performance when walking across three different types of signalized crosswalks.
\end{abstract}

Keywords: pedestrian; gaze behavior; eye-tracking; reaction time; signalized intersection; crossing behavior

\section{Introduction}

According to the European Transport Safety Council (ETSC) PIN report [1], 70\% of all pedestrian deaths occurred in 2017, which happened on urban roads. The same document highlights that pedestrian crossings are a safety issue on the road network, despite being perceived as safe places. The ETSC in [1] clarifies that pedestrians need to be able to see and be seen by other road users and identifies the requirements for pedestrian crossings to be designed to ensure both characteristics. Pedestrians' visual capability is an important characteristic for their safety when approaching the road, and better visual acuity and attention allocation can play a key role when dangerous events occur. Related to these two characteristics is pedestrian reaction time, which is the time it takes for a pedestrian to perceive a particular stimulus. This may be an oncoming vehicle or a traffic signal, depending on the type of pedestrian crossing being studied. One element that has become widespread in recent decades and that greatly affects pedestrians' visual acuity, attention, and reaction time is the use of smartphones while walking. Various authors have addressed the problem of digital blindness in pedestrians [2-4] by naturalistically studying their behavior, demonstrating that mobile phone use is directly associated with an increase in pedestrian injuries and influences pedestrian crossing behavior by encouraging them to make riskier maneuvers. Nevertheless, little research has been developed in relation to the quantification of the effect of different crossing infrastructures as well as other phenomena 
such as digital distraction on the pedestrian glance and behavioral performance while crossing the road $[5,6]$.

The purpose of this study is to analyze how pedestrian crossing infrastructure and smartphone use affect pedestrians' visual attention and reaction time. Unlike the previously cited studies, the present research aims to derive useful information about pedestrians' attention distribution and reaction time from their gaze behavior by using eye-tracking glasses. Furthermore, it attempts to link pedestrians' behavioral variables (waiting time, crossing time, and speed) with the different gaze tendencies to understand whether it is possible to establish a relationship between pedestrians' gaze strategy and their behavior.

\section{Related Works}

Eye-tracking technology is widely used in transportation science, especially in relation to the driving task. Several studies addressed the influence of age $[7,8]$, fatigue $[9,10]$, and distraction [11,12] on driving ability. In addition, some eye-tracking studies have been conducted with cyclists $[13,14]$, not only to observe their gaze behavior but also to derive information about the behavior of motorcyclists, inducing as a hypothesis the similarities in the use of the two modes of transport. Eye-tracking studies have been developing during the last decades also in relation to pedestrians, although they are often conducted indoors. As reported in [15], six research papers have applied eye-tracking techniques to understand how different road environments can affect pedestrians' vision [16-21]. Of these, only three studies conducted outdoor experiments, while the others used simulated scenarios to replicate different road conditions. Most of the listed studies focused on fixation metrics (number and frequency) to identify pedestrian visual strategies. Focusing on outdoor experiments, Dey et al. [18] designed an experiment in which 26 adult participants wearing eye-tracking glasses were asked to cross a road while an instructed car approached and found that their initial fixations focused on the road surface, bumper, hood, and windshield of the car. Geruschat et al. [20] used a head-mounted Iscan on 12 adults-three younger and nine older-to analyze the number of fixations and the direction of their head, with the goal of understanding how they used their vision to safely cross the road. They found that the type of intersection had a major impact on the pedestrians' visual behavior and influenced their exploratory strategy when waiting at the curb: at unsignalized intersections, participants tended to identify a safe gap based on oncoming vehicles, while at signalized intersections, they relied primarily on information from the traffic signal. The authors also indicated that the type of intersection influenced participants' gaze behavior during the crossing procedure as a function of the number of times participants looked to their right. Finally, Jiang et al. [5] used 28 college students in outdoor scenarios to examine the effects of various distracting tasks on their walking ability. The authors instructed participants to first walk without distraction at various street intersections, then listen to music, make a phone call, and finally text. Analysis of pupil dimensions, frequency of scanning, number, and duration of fixations on defined areas of interest (AOIs) showed that texting and phone calls had the greatest impact on pedestrians' behavior by affecting the time it took them to begin crossing the street and their speed, while all types of distractions affected the frequency of scanning. Furthermore, Gruden et al. analyzed the effect of digital distraction on pedestrian behavior and examined the influence of the "check social media" task on pedestrians' reaction time, crossing time, and speed at signalized [6] and unsignalized intersections [21]. In both cases, the results showed a significant difference between the two conditions and quantitatively confirmed that digital blindness is an important issue that should be addressed. Interesting eye-tracking research was developed by Fotios et al. [22], who developed a dual-task method. The method consists in occupying part of the cognitive process of pedestrian participants with a simple task, which is added to their primary task: walking. This method was tested by authors in [23] to understand pedestrian gaze behavior when walking during nighttime, and they found that most of the attention was allocated to other people and the path, suggesting that lighting should be directed towards these elements. The same authors in [24] elaborated on pedestrian attention allocation 
on other walking individuals. They found that participants were more likely to look at people with an unusual gait and that their fixations on these people were longer than the ones on persons with predictable movements. Eye-tracking was also used by [25] to analyze pedestrian fixations during a walk to a café. Authors found that the majority of the fixations were directed to paths and objects (37\% for both stimuli), while $21 \%$ of them were directed to other people. These findings were also confirmed by the study of Davounian and Raynham [26], who found that during nighttime, the path was fixated for a share of $40-50 \%$ of all fixations.

From the literature review, two observations can be drawn: the first one regards the extent of the research about pedestrian digital distraction. Previous works have mainly focused on driver's digital distractions, developing eye-tracking experiments to quantify them. Studies about pedestrian digital distraction are still at a starting point, and many of them have been developed by applying video footage instead of eye-tracking. This methodology, though being very useful and providing many beneficial information, cannot precisely quantify defined variables, such as the time length an individual focuses on a stimulus or his/her reaction time. The second observation is related to the way eyetracking experiments were worked out. Normally, researchers provided participants with very specific tasks, such as solving an easy mathematical formula or answering defined questions. This kind of experiment, which is very structured in regard to the distracting conditions, though being very helpful and controllable by researchers, is still far from the real use of smartphones. Furthermore, to the authors' knowledge, no eye-tracking study addressed the influence of diverse crossing infrastructure on pedestrian attention, though studies about the effect of the infrastructure on drivers' attention allocation were developed [27-30].

With the aim of fulfilling these gaps, in contrast to previous research, this paper aims to demonstrate how different signalized intersection typologies, namely standard intersections, intersections with a traffic light continuous counter (hereafter counter intersections), and intersections with a smart traffic light (hereafter smart traffic light intersections), affect pedestrian behavior and, if solutions for so-called "zombie pedestrians" such as the smart traffic light, positively affect the problem of digital blindness. To achieve these goals, the following research questions were posed:

- does pedestrian attention change as a function of the type of crosswalk signalized?

- does pedestrian reaction time change as a function of signalized crosswalk type?

- does intersection typology affect pedestrian behavior in terms of waiting time, crossing time, and crossing speed?

- do smart traffic signals affect the reaction time of "zombie pedestrians"?

To answer the above questions, the paper is divided into different sections and subsections: First, Section 2 describes the methodology used to develop the experiment by highlighting the location and selection of participants, the main features of the equipment, and the steps to use it accurately, the development of the experiment and its limitations, as well as data elaboration and analysis. Then, the results are presented and discussed in Section 3, dividing them into qualitative and quantitative results. Finally, conclusions are drawn in the last section.

\section{Methodology}

The methodology used in this research, and shown graphically in Figure 1, consists of 4 main steps, each of which is characterized by several sub-steps. In the following subsections, each part of the methodology is addressed and detailly explained. 


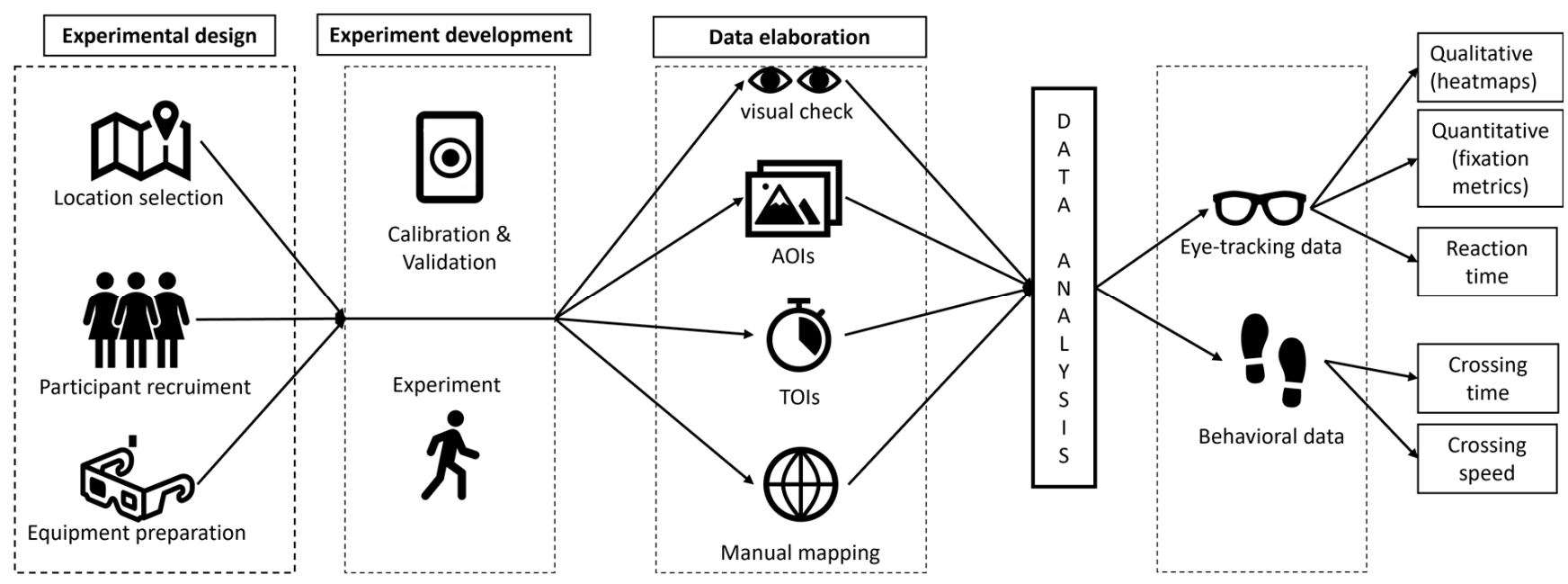

Figure 1. Schematic representation of the methodology followed in the research, from data gathering to the results.

\subsection{Location Selection}

The experiment was conducted in the urban area of Maribor, the second-largest city in Slovenia, where three different intersection typologies were selected: standard signalized pedestrian crossings, signalized pedestrian crossings with a red duration counter, and signalized pedestrian crossings with a red duration counter and a smart traffic light. The term "smart traffic light" refers to a light projected onto the sidewalk that is specifically designed to help smartphone users identify the status of the traffic light. For the first intersection typology, three consecutive pedestrian crossings with the same geometric and technical characteristics were selected (Figure 2a). They all belong to the same intersection that connects two major city streets. These crossings are all characterized by a pedestrian green traffic light duration of $7 \mathrm{~s}$ and a variable red traffic light duration that depends on the pedestrian call button. The traffic light itself is characterized by a simple 2-light signalization and no red-light duration counter. The geometric characteristics of the crosswalks and the traffic flow on the linked roads are summarized in Table 1.

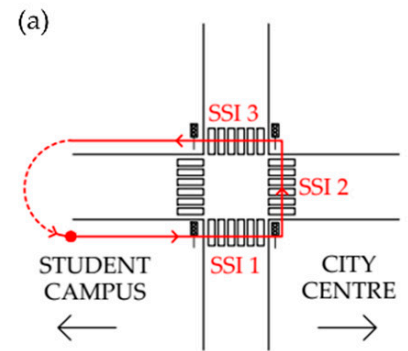

(b)

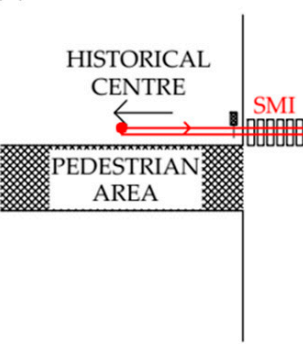

(c)
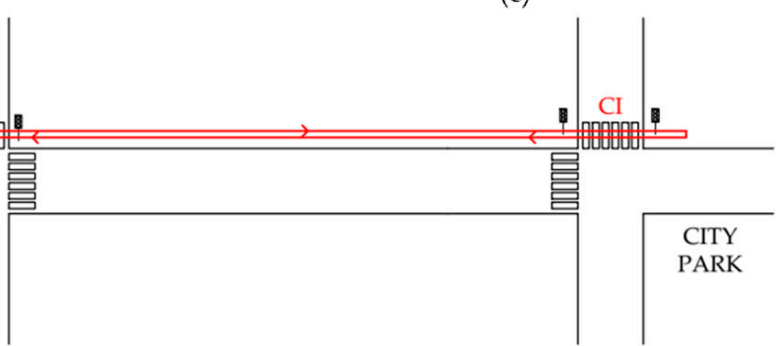

Figure 2. Representation (not in scale) of the signalized intersections, that participants crossed during the eye-tracking experiment: (a) standard signalized intersections (SSI 1; SSI 2; SSI 3); (b) smart traffic light intersection (SMI); (c) counter intersection (CI). 
Table 1. Geometric and flow data at the various signalized intersections under study.

\begin{tabular}{cccccc}
\hline Signalized Crossing Typology & Width (m) & Length (m) & $\begin{array}{c}\text { One/ } \\
\text { Bi-Directional }\end{array}$ & Number of Lanes & $\begin{array}{c}\text { Flow } \\
(\mathbf{v e h} / \mathbf{h r})\end{array}$ \\
\hline Standard signalized crossing 1 (SSI 1) & 5.85 & 16.00 & Bi-directional & 3 & 540 \\
Standard signalized crossing 2 (SSI 2) & 6.00 & 8.30 & Bi-directional & 3 & 600 \\
Standard signalized crossing 3 (SSI 3) & 5.70 & 12.00 & Bi-directional & 3 & 2 \\
Signalized crossing with counter (CI) & 3.35 & 6.00 & One-directional & 480 & 486 \\
Signalized crossing with smart traffic & 4.00 & 7.00 & One-directional & 2 & 665 \\
light (SMI) & & & & \\
\hline
\end{tabular}

The second type of crosswalk is a signalized crosswalk with a red-light duration counter (Figure 2c). This crosswalk is located near the city park and, similar to the previous ones, crosses an urban one-way street with high traffic volumes (Table 1). The width and length of the crosswalk are $3.35 \mathrm{~m}$ and $6.00 \mathrm{~m}$, respectively. The duration of the green light is $6 \mathrm{~s}$, and that of the red-light duration is variable such as at the previous crosswalk typology.

The last selected crosswalk is characterized by a smart traffic light, which consists of a normal traffic light with the addition of a red-light duration counter and a smart traffic light projected on the pavement (Figure 2b). It should be noted here that in this case study, the intelligent traffic light only projects the red light onto the sidewalk on both sides of the intersection, while the light disappears when it turns green. This crossing is not far from the previous intersection and crosses one of the main one-way streets in the city. As with the previous cases, the traffic flow data are summarized in Table 1.

While selecting these intersections, two important issues were faced: first, to find signalized intersections having a similar traffic light cycle; second, to find intersections with a sufficient vehicular flow to have similar conditions for each participant, while being always careful to participants' safety. Since all participants were adults, and vehicular and pedestrian flows were separated in time thanks to the traffic lights, no specific safety issues could be foreseen. Therefore, road crossings were chosen, where a high vehicular flow is present and where normally also a consistent number of pedestrians is visible. The aim was to have a high number of stimuli and to ensure the most similar external conditions as possible for all participants. Of course, when developing field experiments, a certain variability should be considered, but the requirements decided when designing the experiment, and met with the current selection of intersection, allowed us to fulfill these aspects. Another issue was that only one smart light intersection was present in the city at the time of the experiment, and, therefore, data from this intersection typology could be restrained. To overcome this problem, participants were asked to cross the road on the same intersection twice for each phone condition, when going and when coming back.

\subsection{Participant Selection}

A total of 26 volunteer participants were recruited for the experiment among the students of the University of Maribor. Of these, 16 were female, and 10 were male. The participants had to meet two sets of inclusion criteria: the first related to general characteristics of the individual and allowed to select only volunteers with a common background, the second related to the functioning of the eye-tracking sensors and allowed to avoid bias. In the first group of personal characteristics, there were the following three criteria: age between 20 and 26 years, normal walking ability, possession of a smartphone. In the second group of criteria, there were: no to slight vision correction, not wearing glasses, and no to slight makeup in the eye area.

\subsection{Equipment}

The equipment used for this experiment is a pair of Tobii Pro 2 eye-tracking glasses. This device consists of three main units-the head unit, which consists of the glasses themselves, the head unit, and the tablet. On the head unit is the whole sensory part: 2 sensors for pupil detection for each eye, a scene camera, a gyroscope, and an accelerometer. The 
head unit is connected to the main unit via an HDMI cable. The main unit houses all the hardware components that allow the glasses to operate and store data.

Finally, a tablet is a portable carrier for the Tobii software. Both Tobii Controller and Tobii Analyzer are installed on it. The former allows you to check the status of recordings in real-time and manage them. The second software, which can also be installed on other devices, enables data elaboration and analysis.

\subsection{Development of the Experiment}

For each participant, the experiment was developed in two steps: first, the calibration and validation of the equipment were performed, then the actual experiment could begin

The steps of calibration and validation are two essential elements in the development of the experiment. Namely, they ensure that the eye model created by the eye-tracking device is tailored to the individual subject. While these two steps can be performed once for screen-based eye trackers and used for multiple subjects, eye-tracking glasses require a new calibration and validation step for each participant.

The calibration step consists of a one-point calibration and is performed on the Tobii Controller: each participant should look at a specific card, on which a point in a target is drawn until the software indicates that the calibration was successful. To check the calibration results and ensure that there are no major discrepancies between the expected fixation point and the one detected by the software, validation was also performed. It consists of asking participants to look at specific objects and check whether their gaze point matches the specified object. In this study, a two-step validation was conducted: first, participants were asked to look at specific objects in an indoor environment, then the same procedure was performed outdoors. This was particularly important because the experiment itself was conducted outdoors under changing lighting conditions and stimuli. After these steps, the actual experiment could be conducted. Each participant was asked to walk the set route twice, first checking their social media on their phone and then without any technological devices. For the three standard signalized intersections, participants crossed them once with their phone and once without it. For the remaining intersections (with counter and with counter and smart traffic light), they were asked to cross them twice with a phone and twice without a phone (to return to the starting point). In this way, 14 crossing actions were identified for each participant, 6 for the standard intersection, 4 for the signalized intersection with counter, and 4 for the signalized intersection with counter and smart traffic light.

\section{Limitations}

Some limitations of the study should be highlighted. First, it should be considered that although the eye-tracking glasses are a really unintrusive device, the participants are aware of wearing them, which could slightly influence their behavior. Furthermore, some of them (especially female participants) might find it uncomfortable to meet other people on the street and change their field of vision. Finally, peripheral vision, which is often used to make quick glances at elements that do not fall within the main cone of vision, is not captured by eye-tracking devices. Nevertheless, eye tracking provides very accurate and reliable information about processes that cannot be easily studied using other techniques.

Considering the whole experimental setup, a research limitation could be seen in the number of participants: indeed, though it was chosen considering the average number of participants found in similar literature studies, a higher number of participants could improve the results. Furthermore, in such experiments, an important effect is played by demographic, personality, and situational variables [31,32]. Aspects such as the age and gender of participants could highly affect the study results. For this reason, this research focuses on one specific pedestrian group, young adults, that are also the ones more prone to use smartphones in their everyday activities. Furthermore, personality traits are not considered at this point, but they could provide interesting insights in further research. Finally, among all possible situational variables, the use of smartphones was selected, but 
other situations, e.g., police reinforcement, as underlined by [31], can affect pedestrian behavior as well.

\section{Data Elaboration}

Once the experiment was complete and all participants' videos were recorded, the raw data collected was to be analyzed to obtain useful gaze metrics. This was performed in four steps (Figure 1):

- An initial visual analysis of the collected video footage was conducted for several purposes. First, it helped to understand which elements were of interest to the participants and which were related to the aim of the present research. Second, the visual analysis allowed for the identification of common and divergent patterns of participant behavior, which facilitated the interpretation of the results during the analysis process. Finally, it was possible to define the starting and ending points (both temporal and spatial) as well as the duration of the crossing experience. The term "crossing experience" refers to the time period during which participants arrive at the intersection, stay there, wait for the green light, and cross the street to eventually reach the opposite safe side. It is clear that the crossing experience, during which data are continuously recorded, is not the same as the crossing action. This can be defined as the action that participants develop from the moment they leave the first safe side (when they first set foot on the roadway) to the moment they reach the opposite side (when they are fully on the opposite sidewalk). The crossing experience is composed of a waiting time, a reaction time, and a crossing time, so the crossing action is only part of it. This specification is important to understand the following results.

- After visually examining the video footage, areas of interest should be defined. These areas are very important tools in the Tobii processing software, as they allow gaze data to be aggregated based on elements that fit the goals of the individual investigation. They are created directly on the snapshot used to assign gaze items and basically function like "virtual masks" that collect all gaze items that fall within their scope. In this research, seven groups of AOIs were defined and are summarized below:

- Traffic light components: Specific AOIs were defined for the red and green traffic lights, the continuous red counter, the intelligent traffic light, and the pedestrian call button.

- Pedestrian flows: Pedestrians walking on the same or opposite sidewalk and pedestrians crossing the crosswalks in the same or opposite direction were also defined by specific AOIs.

- Bicycle traffic: bicyclists traveling in the same or opposite direction were also considered and defined as AOIs.

- Motor vehicle traffic: AOIs were defined for oncoming cars, cars waiting at the stop line, and cars exiting the intersection.

- Roadway elements: sidewalks and pavement, crosswalks, bike lanes, and traffic signs are among the elements considered that may affect pedestrian viewing patterns.

- Other elements not directly related to street design: parked cars, obstacles on the sidewalk, other lights and objects, and passing bicyclists and pedestrians (not involved in the crossing action) were considered.

$\bigcirc \quad$ Phone: a specific AOI was defined for smartphone use.

- After the spatial aggregation of the data by the AOIs, it is useful to perform a temporal aggregation of the same, which can be performed by the so-called times of interest (TOIs). Times of interest are selected periods of the video recording in which eye movement data is mapped and clearly referred to in the quantitative results, the metrics. In the present study, each crossing experience coincides with a TOI. In this way, the final results indicate which elements (AOIs) were observed during each specific crossing experience (TOI). 
- Finally, after identifying the AOIs and TOIs, you can proceed with the manual assignment. This process consists in manually defining, on the selected snapshot, to which AOI a specific viewpoint belongs. This process leads to the final outputs of the software, which can then be exported as qualitative plots and quantitative variables. Both types of outputs are considered and applied in the following analyzes.

\section{Data Analysis}

Data analysis was conducted using three different types of data:

- Qualitative representations of participants' gaze behavior: there are two graphical representations of fixations-heat maps and gaze plots. The first shows the duration and/or the number of fixations on the defined areas of interest. The second represents the sequence followed by each participant's eyes. While heat maps are based on color-coding, where red areas are the most fixated and green areas are the least observed, gaze plots consist of a series of points, whose dimensions are related to the duration/number of fixations and represent the path followed by the gaze.

- Quantitative data on participant gaze behavior: these data include events, visits, and fixation data that have already been aggregated based on the defined AOIs and TOIs. In this study, the number of fixations, fixation duration, time to the first fixation, and duration of the first fixation are the data considered in the analysis.

- Quantitative data on participants' crossing behavior: in this data, waiting time, crossing time, and crossing speed are considered. These variables are not directly output by the eye-tracking software but were measured from eye-tracking records. Waiting time is the time the participant waits to cross the road. It is defined as the time difference between the moment the participant arrives and stops at the intersection and the moment he/she starts crossing. The minimum value of the waiting time is $0 \mathrm{~s}$ if the participant meets a green light or disregards a red light. The crossing time is defined as the time from the moment the participant leaves the sidewalk with the first foot to the moment he/she is completely on the opposite safe side. It is also measured in seconds [s]. Finally, the crossing speed is calculated as the ratio between the length of the crossing in meters $[\mathrm{m}]$ and the crossing time $[\mathrm{s}]$.

\section{Results}

To understand whether there is a difference in the gaze and crossing behavior of pedestrians at the three crosswalk typologies, a comparative analysis is elaborated. First, differences and similarities are qualitatively highlighted using heat maps. Then, the fixation data will be statistically described and tested to understand if there is a statistical difference between the three samples. Finally, a similar statistical analysis of the crossing variables will be conducted to determine if a difference in gaze behavior is also associated with a difference in overall pedestrian crossing performance.

\subsection{Qualitative Results}

To understand how pedestrians allocate their attention when crossing the road, a comparison of heat maps created from participants' tracked gaze is developed. In Figure 3, each row of images (e.g., a-a') represents the attention allocation of all participants on the same crosswalk typology, under two conditions: without a phone (a) and with a phone ( $\left.a^{\prime}\right)$. As it can be seen, when people are handling the phone, they focus heavily on the device and look only at a few other elements at the smart crosswalk. When approaching the intersection without a phone, their eyes focus on a larger number of elements. It is remarkable how large the difference is between the two conditions when it comes to conflicting vehicles. From this initial qualitative analysis, it can be concluded that the traffic light, the sidewalk, and oncoming vehicles are the three elements that attract pedestrians' attention while walking without a phone. While the phone is the main element that disturbs the other situation. Comparing the heatmaps in terms of intersection typology and considering only the situation without a phone, it can be observed that at the standard crosswalk, most of 
the attention is focused on the pavement/sidewalk and other objects, followed by the red traffic light. On the other hand, the counter crosswalk and the smart light crosswalk are characterized by a number of fixations on the counter, the red traffic light, and other objects not directly related to the street design. Considering also the condition with a phone, it can be observed that the smartphone has a high effect on pedestrian glance performance, especially at standard and counter intersections, being the participants focused only on it. At the smart light crossing, participants also look at other elements of the street design while handling their phones, such as the counter and the red light. Nevertheless, these looks are much less intense than in the condition without a phone at the same intersection.

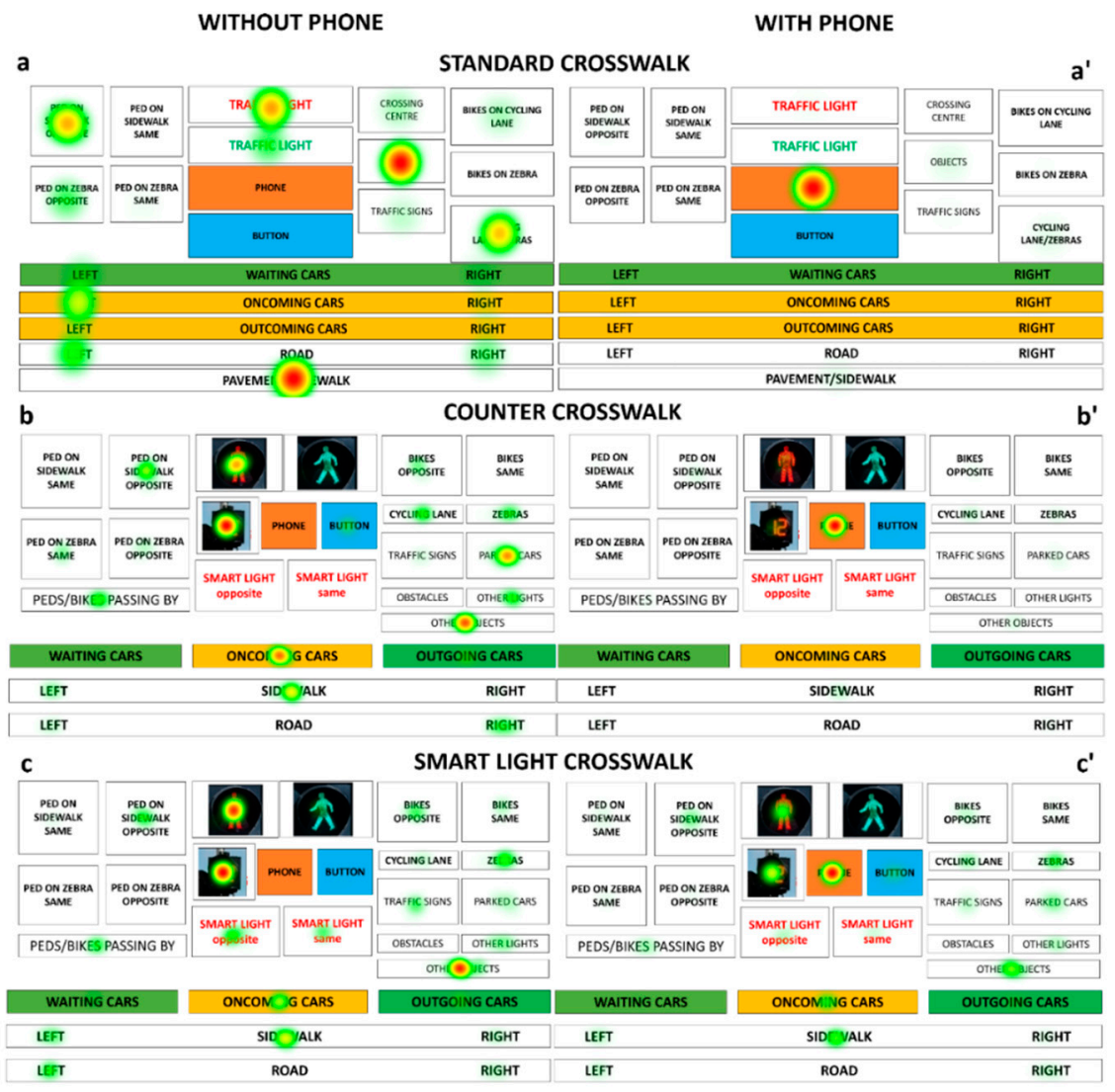

Figure 3. Heatmaps of pedestrian gaze behavior while walking with the phone $\left(\mathbf{a}^{\prime}-\mathbf{c}^{\prime}\right)$ and without the phone $(\mathbf{a}-\mathbf{c})$. The rows of images refer respectively to: $\left(\mathbf{a}, \mathbf{a}^{\prime}\right)$ standard crosswalk; $\left(\mathbf{b}, \mathbf{b}^{\prime}\right)$ counter crosswalk; (c, $\left.\mathbf{c}^{\prime}\right)$ smart light crosswalk.

\subsection{Quantitative Results}

To support the previous rough conclusions, a quantitative analysis of the number and duration of fixations is performed. Table 2 summarizes the average number of fixations by participants for each AOI considered at the three crosswalk typologies for the two conditions. In the "no phone" condition, oncoming vehicles are the most observed element at the standard and counter crosswalk, while they are not as much fixed at the smart traffic light, as attention is maintained on the zebras/bike lanes and bicycles. As already identified through the heatmaps, most attention is paid to the phone while it is being operated. After that, the sidewalk/pavement is the most fixated area at standard crosswalks, while the zebras/bike lanes are the most observed at the other two typologies. Of interest is the gaze behavior related to other objects and traffic signs: the former is observed particularly frequently when subjects are walking without the phone, while they are observed only marginally when checking the device. The second group has a low number of fixations in both conditions. In addition to the number of fixations, their duration is also a very important element to assess the attention distribution of pedestrians. Figures 4-6 show 
the share of time participants spent on each AOI in the two conditions for each crosswalk typology, with Figure 6 showing results for the situation "with phone" without plotting the AOI related to the device. It is interesting to notice that in the situation "without phone", when participants were specifically told to not handle their device, still some of them used it. For this reason, a rate of time on AOI "phone" can be observed in Figure 4.

Table 2. Average number of fixations on each defined AOI at the three crosswalk typologies in both conditions (with phone/without phone).

\begin{tabular}{|c|c|c|c|c|c|c|}
\hline \multirow[b]{2}{*}{ AOIs } & \multicolumn{3}{|c|}{ Without Phone } & \multicolumn{3}{|c|}{ With Phone } \\
\hline & $\begin{array}{l}\text { Standard } \\
\text { Crosswalk }\end{array}$ & $\begin{array}{l}\text { Counter } \\
\text { Crosswalk }\end{array}$ & $\begin{array}{l}\text { Smart Light } \\
\text { Crosswalk }\end{array}$ & $\begin{array}{c}\text { Standard } \\
\text { Crosswalk }\end{array}$ & $\begin{array}{l}\text { Counter } \\
\text { Crosswalk }\end{array}$ & $\begin{array}{l}\text { Smart Light } \\
\text { Crosswalk }\end{array}$ \\
\hline Bikes & 2.3 & 3.8 & 8.9 & 0.3 & 3.5 & 3.8 \\
\hline Button & 1.0 & 2.2 & 1.0 & 1.5 & 1.7 & 5.9 \\
\hline Countdown & 0.0 & 5.9 & 7.4 & 0.0 & 3.2 & 16.9 \\
\hline Cycling lane/zebras & 9.4 & 8.7 & 9.2 & 3.9 & 6.1 & 21.8 \\
\hline Green light & 2.2 & 1.3 & 1.3 & 1.4 & 1.4 & 2.4 \\
\hline Oncoming cars & 12.8 & 8.9 & 5.5 & 3.6 & 3.3 & 12.7 \\
\hline Other objects & 10.4 & 6.3 & 8.9 & 2.8 & 0.0 & 0.5 \\
\hline Outgoing cars & 5.1 & 2.5 & 2.7 & 2.6 & 3.3 & 12.7 \\
\hline Ped on sidewalk opposite & 4.4 & 4.4 & 5.1 & 2.5 & 2.9 & 10.0 \\
\hline Ped on sidewalk same & 2.5 & 2.0 & 3.3 & 0.3 & 2.4 & 3.0 \\
\hline Ped on zebra opposite & 1.7 & 1.5 & 0.5 & 0.3 & 1.7 & 1.5 \\
\hline Ped on zebra same & 1.7 & 2.8 & 0.0 & 0.3 & 3.3 & 2.6 \\
\hline Phone & 0.0 & 0.0 & 2.0 & 32.9 & 34.2 & 45.5 \\
\hline Red-light & 5.6 & 6.2 & 7.1 & 4.0 & 3.1 & 14.2 \\
\hline Road left & 2.6 & 1.9 & 3.3 & 1.0 & 1,2 & 3.7 \\
\hline Road right & 2.0 & 2.8 & 3.3 & 1.0 & 2,7 & 6.5 \\
\hline Sidewalk/pavement & 8.5 & 6.6 & 7.5 & 4.6 & 3.8 & 21.7 \\
\hline Smart light opposite & 0.0 & 0.0 & 2.8 & 0.0 & 0.0 & 4.1 \\
\hline Smart light same & 0.0 & 0.0 & 3.1 & 0.0 & 0.0 & 4.6 \\
\hline Traffic Signs & 1.4 & 1.3 & 2.9 & 0.9 & 1.5 & 2.1 \\
\hline Waiting cars & 5.3 & 1.2 & 1.5 & 1.8 & 2.3 & 1.6 \\
\hline
\end{tabular}

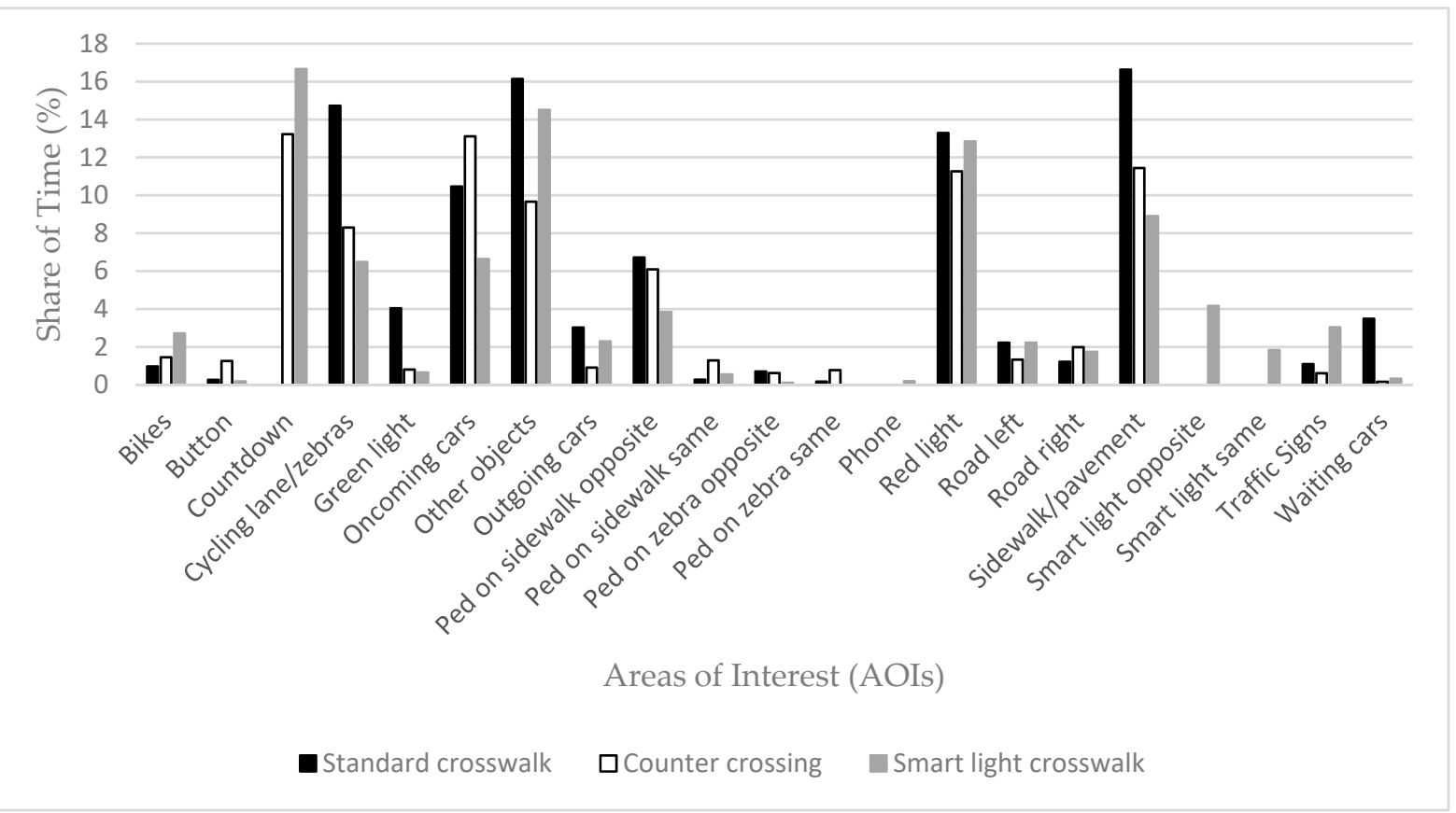

Figure 4. Share of time participants fixated the defined AOIs on the three different crosswalk typologies-comparison of the values in the condition without phone. 


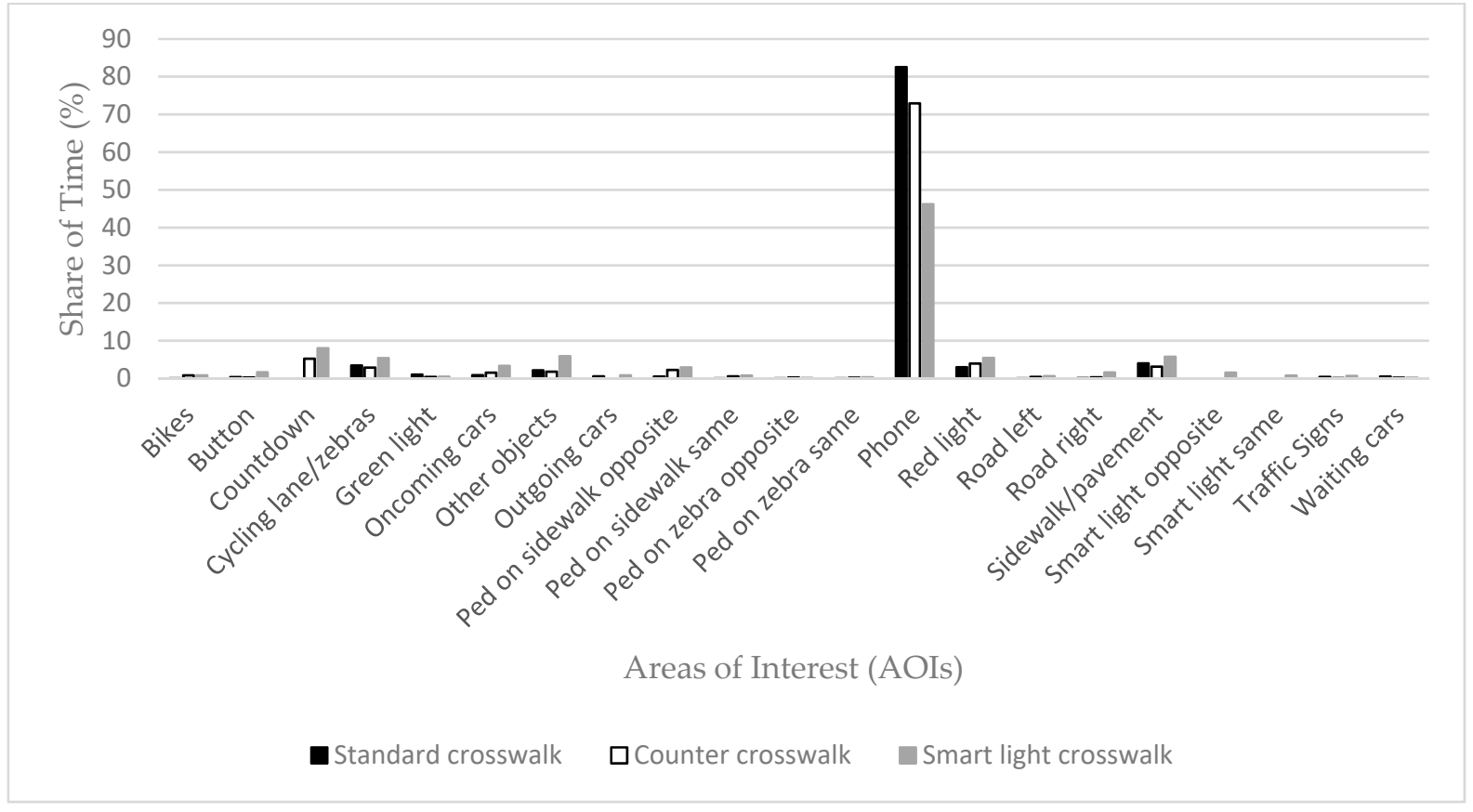

Figure 5. Share of time participants fixated the defined AOIs on the three different crosswalk typologies-comparison of the values in the condition with phone.

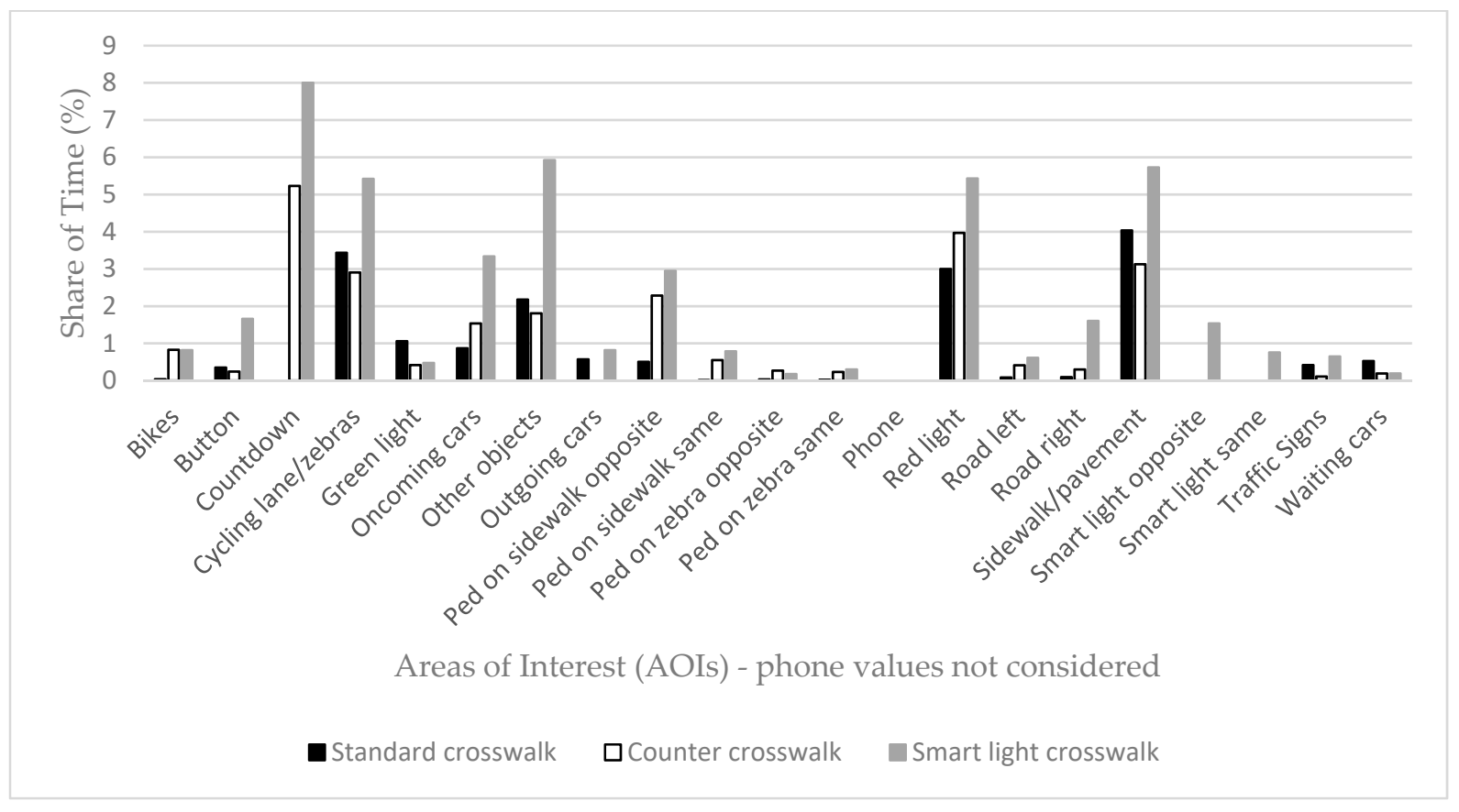

Figure 6. Share of time participants fixated the defined AOIs on the three different crosswalk typologies-comparison of the values in the condition with phone (no AOI "phone").

\subsubsection{Reaction Time}

To answer the second research question at the basis of this work, a statistical analysis of reaction time samples was developed. First, descriptive statistics of reaction time at the three different crosswalk typologies were calculated (Table 3). Considering the whole database of reaction time (i.e., measured when participants were both handling and not handling their device), it can be seen that the mean reaction time values differ from one intersection typology to the others. It appears that pedestrians have shorter reaction times 
at counter crosswalks, while they are higher at standard and smart light intersections, with standard crosswalks having the highest values.

Table 3. Descriptive statistics of reaction time on the three crosswalk typologies.

\begin{tabular}{cccc}
\hline Descriptive Statistics & Standard Crosswalk & Counter Crosswalk & Smart Light Crosswalk \\
\hline Mean & 1.288 & 0.786 & 1.270 \\
Standard error & 0.288 & 0.116 & 0.202 \\
Asymmetry & 3.67 & 1.58 & 3.15 \\
Minimum & 0.016 & 0 & 0 \\
Maximum & 11.905 & 2.546 & 9.037 \\
\hline
\end{tabular}

In order to be able to select the correct statistical tests, the Anderson-Darling test was devised to check the normality of the sample. This test compares the calculated $p$-value with the selected $\alpha$-level, and on this basis, indicates whether the samples are normally distributed $(p$-value $>\alpha)$ or not $(p$-value $<\alpha)$. Table 4 summarizes the results and shows that none of the samples is normally distributed. Therefore, two non-parametric tests were selected to determine if reaction times at the three different types of crosswalks were statistically different: Kruskal-Wallis and mean-median tests. The first is powerful for data from many distributions, while the second is robust to outliers [33].

Table 4. Anderson-Darling (AD) test results for reaction time on the three crosswalk typologies.

\begin{tabular}{cccc}
\hline & Standard Crosswalk & Counter Crosswalk & \multicolumn{2}{c}{ Smart Light Crosswalk } \\
\hline mean & 1.288 & 0.7856 & 1.270 \\
\hline standard deviation & 1.977 & 0.8498 & 1.473 \\
test statistics & 14.694 & 3.045 & 3.360 \\
$p$-value & $<0.005$ & $<0.005$ & $<0.005$ \\
$\alpha$-level & 0.05 & 0.05 & 0.05 \\
\hline
\end{tabular}

The results show (Table 5) that reaction times at the three intersections are statistically different for a significance level of 0.10 . Indeed, the Kruskal-Wallis test turns a $p$-value equal to 0.10 , while Mood's median gives a $p$-value much lower than 0.10 . Nevertheless, we cannot say that there is a significant difference for a stricter $\alpha$-level (the usual 0.05). At this point, it should be mentioned that the participants who approached the crosswalk with the counter and smart light were very likely to cross the street before the green light appeared, resulting in a loss of reaction time data. In fact, they used the information from the counter to cross the street earlier, but only when there were no vehicles or they were stationary. So, though we can fairly admit that crosswalk typology affects pedestrian reaction time, a higher number of regular crossing actions (without red violations) would help confirm this finding.

Also, it is interesting to highlight if the presence of the phone influences or not pedestrian reaction time. Since both samples of measures-the one with phone and the one without the phone-are not normal (the Anderson-Darling test run on these two samples turned a $p$-value much lower than the $\alpha$-level of 0.05), a Mann-Whitney test was run, which compares the median of the two samples and defines if they are significantly different or not. Results indicate that there is a statistical difference in reaction time when people look at their social media and when they do not do so: indeed, the $p$-value calculated by the test is lower than the 0.05 threshold set for the significance level. This finding is also strengthened by the confidence interval found by the same test, which at a $95 \%$ confidence level is $(-0.5047 ;-0.0603)$ and does not contain 0 , indicating a statistical difference between the medians of the two samples. 
Table 5. Kruskal-Wallis and Mood's median non-parametric test results for reaction time on the three crosswalk typologies.

\begin{tabular}{cccccc}
\hline Test & \multicolumn{2}{c}{ Kruskal-Wallis } & \multicolumn{2}{c}{ Mood's Median } \\
\hline Crossing Typology & Median & Average Rank & Z & Median & Q3-Q1 \\
\hline Standard crosswalk & 0.4824 & 77.4 & 1.00 & 0.4824 & 1.764 \\
Counter crosswalk & 0.4505 & 68.5 & -1.48 & 0.4505 & 1.059 \\
Smart light crosswalk & 0.8540 & 86.8 & 0.40 & 0.8540 & 0.625 \\
Overall & & 77.5 & Chi-square & 5.23 \\
H & 4.53 & H (adjusted for ties) & 4.53 & P & 0.07 \\
P & 0.10 & P (adjusted for ties) & 0.104 & & \\
\hline
\end{tabular}

\subsubsection{Crossing Behavior}

Three variables were considered in the analysis of pedestrian crossing behavior: waiting time, crossing time, and crossing speed. The first one provides information about the delay experienced and accepted by pedestrians at the three different types of intersections, while the crossing time and crossing speed provide information about pedestrian behavior during the crossing action.

\section{Waiting Time}

To understand which delay is experienced by pedestrians at the three different intersection typologies, waiting time was calculated as the time from the beginning of the crossing experience, i.e., the moment the participant arrived on the sidewalk to the moment he/she started crossing.

In Table 6, the mean values and standard errors for waiting time for the three different crossing typologies are reported. Furthermore, it is expected that different crosswalk typologies show different waiting times, and to confirm it, after results from the AndersonDarling test that the samples are normally distributed, a one-way ANOVA was developed (Table 7).

Table 6. Mean values and standard errors of pedestrian waiting time [s] at the three types of crosswalk.

\begin{tabular}{cccc}
\hline & Standard Crosswalk & Counter Crosswalk & Smart Crosswalk \\
\hline Mean value & 18.38 & 27.30 & 24.58 \\
Standard error & 1.98 & 1.91 & 1.80 \\
\hline
\end{tabular}

Table 7. Results of one-way ANOVA for pedestrian waiting time [s] at the three types of crosswalk.

\begin{tabular}{cccc}
\hline & Standard Crosswalk & Counter Crosswalk & Smart Crosswalk \\
\hline Mean value & 18.38 & 27.30 & 24.58 \\
$95 \%$ confidence interval & $(14.86 ; 21.90)$ & $(23.34 ; 31.25)$ & $(20.59 ; 28.58)$ \\
$p$-value & 0.003 & 0.003 & 0.003 \\
\hline
\end{tabular}

Comparing average reaction times calculated in Section 6.2.1. to average waiting times, it cannot be said that a direct relationship between the two does exist: indeed, a common trend of the two times cannot be observed. Nevertheless, this aspect could be an interesting point to tackle in future research works, outlining if the experienced delay affects the reactions of pedestrians.

\section{Crossing Time}

When analyzing pedestrian crossing time, it should be considered that it is closely related to the length of the crossing. In this case, handling the phone could have an effect on pedestrian behavior. Hence, the next analyses consider the two different conditions-with 
a phone and without a phone. Already in Table 8, a big difference can be seen between the mean values of crossing time for the standard crosswalks and for counter and smart light crosswalks. Nevertheless, some observations can be made, both in relation to the statistics in Table 8 and to the trends in Figures 7 and 8. First, it is interesting to note that the time to cross the intersection seems to be shorter when handling the phone at both counter crosswalk and smart light crosswalk, while the opposite is true at the standard signalized intersection. Looking at Figure 7, the crossing time when walking without the smartphone shows a peak in the $[4,5] \mathrm{s}$ and $[5,6] \mathrm{s}$ intervals for counter and smart crosswalk, respectively, while it shows a more distributed trend for standard crosswalks, with values ranging from $7 \mathrm{~s}$ to $10 \mathrm{~s}$. On the other hand, all three types of crosswalks show a clear peak when handling the phone, with values for crossing time ranging from $[9,10] \mathrm{s}$ for the standard crosswalks.

Table 8. Descriptive statistics of crossing time on the three crosswalk typologies when participants do not handle their phone.

\begin{tabular}{|c|c|c|c|c|c|c|}
\hline & \multicolumn{2}{|c|}{ Standard Crosswalk } & \multicolumn{2}{|c|}{ Counter Crosswalk } & \multicolumn{2}{|c|}{ Smart Light Crosswalk } \\
\hline & Without Phone & With Phone & Without Phone & With Phone & Without Phone & With Phone \\
\hline Mean & 8.86 & 9.16 & 4.14 & 3.96 & 5.44 & 5.23 \\
\hline Standard error & 0.28 & 0.33 & 0.13 & 0.12 & 0.15 & 0.19 \\
\hline Asymmetry & 0.83 & 0.69 & 0.47 & 0.01 & 1.41 & 2.16 \\
\hline Minimum & 6.78 & 6.22 & 3.00 & 3.00 & 4.00 & 4.00 \\
\hline Maximum & 12.69 & 13.08 & 6.00 & 5.00 & 8.00 & 9.00 \\
\hline Level of confidence & 0.58 & 0.67 & 0.27 & 0.24 & 0.32 & 0.40 \\
\hline
\end{tabular}

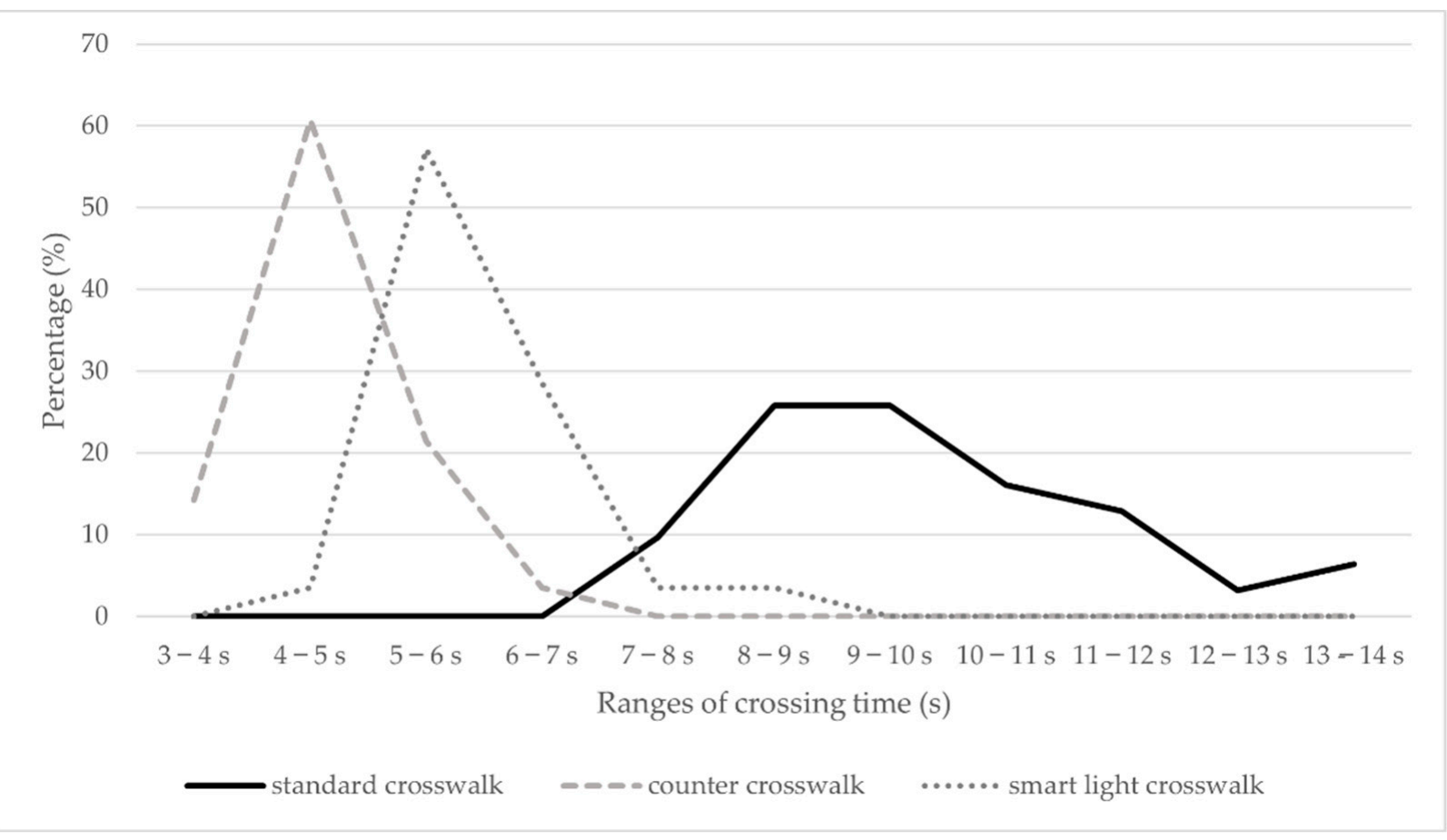

Figure 7. Trend of crossing time on the three crosswalk typologies when walking without the phone. 


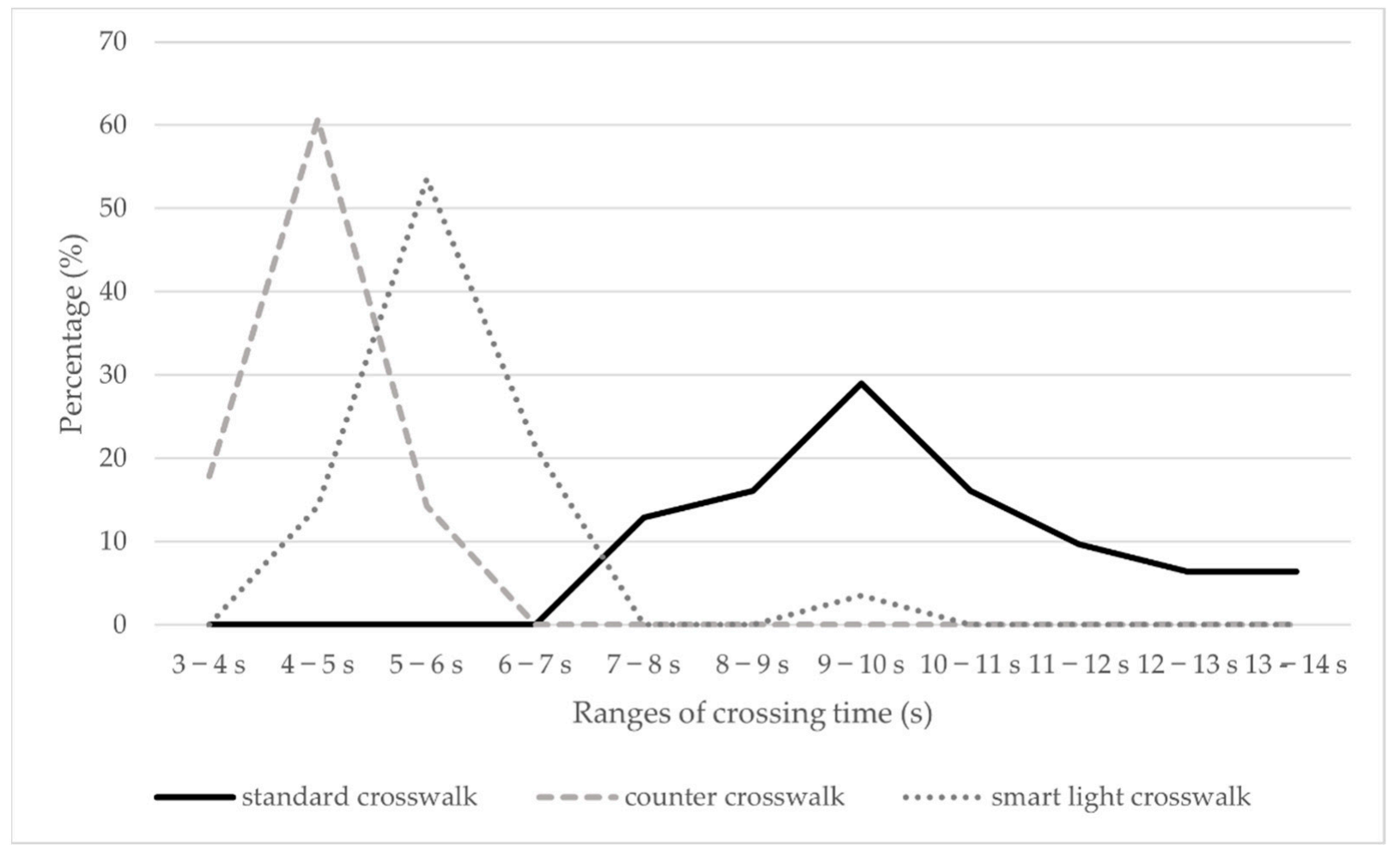

Figure 8. Trend of crossing time on the three crosswalk typologies when walking with the phone.

Crossing Speed

Statistical analysis was performed for crossing speed to determine if there is a statistical difference in pedestrian behavior at the three intersection typologies. The descriptive statistics (Tables 9 and 10) show different mean values of speed decreasing from standard to counter and smart light crosswalks. Comparing the situation with and without the phone, it can be noticed that speed slows down when crossing the crosswalk with the phone, while it increases for the other two types. This effect could be due to the presence of the counter, which shows pedestrians not only the duration of the red light, but also how much time they have to cross the road safely.

Table 9. Descriptive statistics of crossing speed on the three crosswalk typologies when participants do not handle their phone.

\begin{tabular}{cccc}
\hline Descriptive Statistics & Standard Crosswalk & Counter Crosswalk & $\begin{array}{c}\text { Smart Light } \\
\text { Crosswalk }\end{array}$ \\
\hline Mean & 1.61 & 1.49 & 1.31 \\
Standard error & 0.03 & 0.05 & 0.03 \\
Asymmetry & -0.14 & 0.63 & -0.31 \\
Minimum & 1.26 & 1.00 & 0.88 \\
Maximum & 1.94 & 2.00 & 1.75 \\
Level of confidence & 0.06 & 0.10 & 0.07 \\
\hline
\end{tabular}

Considering the asymmetry values, the normality of the samples could not be confirmed initially. Therefore, the Anderson-Darling test and the Kolmogorov-Smirnov test were used to determine whether the crossing rate was normally distributed among the three crossing typologies. Both tests check the $p$-value against a chosen $\alpha$-level, in this case, $\alpha=0.05$, and confirm or reject the hypothesis H0. Tables 11 and 12 show the results of the tests for the situation with a phone (Table 12) and without a phone (Table 11). Interestingly, the two tests agree in all cases and show that the speed distribution is normal at standard crossings, while it is not normally distributed at the counter and smart light 
crosswalks. Based on these results, Kruskal-Wallis and mean-median non-parametric tests were also performed for the speed samples at intersections. Again, the two tests agree (Tables 13 and 14), confirming that the three speed samples are statistically different: both $p$-values are below the chosen $\alpha$-level.

Table 10. Descriptive statistics of crossing speed on the three crosswalk typologies when participants do handle their phone.

\begin{tabular}{cccc}
\hline Descriptive Statistics & Standard Crosswalk & Counter Crosswalk & $\begin{array}{c}\text { Smart Light } \\
\text { Crosswalk }\end{array}$ \\
\hline Mean & 1.57 & 1.55 & 1.38 \\
Standard error & 0.04 & 0.05 & 0.04 \\
Asymmetry & 0.69 & 0.80 & -0.25 \\
Minimum & 1.22 & 1.20 & 0.78 \\
Maximum & 2.07 & 2.00 & 1.75 \\
Level of confidence & 0.08 & 0.10 & 0.09 \\
\hline
\end{tabular}

Table 11. Anderson-Darling (AD) and Kolmogorov-Smirnov (KS) test results for crossing speed on the three crosswalk typologies when participants do not handle their phone.

\begin{tabular}{ccccccc}
\hline Descriptive Statistics & \multicolumn{2}{c}{ Standard Crosswalk } & \multicolumn{2}{c}{ Counter Crosswalk } & \multicolumn{2}{c}{ Smart Light Crosswalk } \\
& AD & KS & AD & KS & AD & 1.31 \\
& 1.608 & 1.608 & 1.489 & 1.489 & 1.31 & 0.1724 \\
mean & 0.1674 & 0.1674 & 0.2572 & 0.2572 & 0.1724 & 0.33 \\
standard deviation & 0.363 & 0.096 & 2.897 & 0.341 & $<.788$ & $<0.005$ \\
test statistics & 0.419 & $>0.150$ & $<0.005$ & $<0.010$ & 0.05 & 0.05 \\
$p$-value & 0.05 & 0.05 & 0.05 & 0.05 & 0.05 \\
$\alpha$-level & & &
\end{tabular}

Table 12. Anderson-Darling (AD) and Kolmogorov-Smirnov (KS) test results for crossing speed on the three crosswalk typologies when participants do handle their phone.

\begin{tabular}{ccccccc}
\hline Descriptive Statistics & \multicolumn{2}{c}{ Standard Crosswalk } & \multicolumn{2}{c}{ Counter Crosswalk } & \multicolumn{2}{c}{ Smart Light Crosswalk } \\
& AD & KS & AD & KS & AD & 1.376 \\
mean & 1.57 & 1.57 & 1.55 & 1.55 & 0.2181 & 0.2181 \\
standard deviation & 0.2292 & 0.2292 & 0.2486 & 0.2486 & 2.256 & 0.302 \\
test statistics & 0.627 & 0.14 & 3.507 & 0.387 & $<0$ \\
$p$-value & 0.093 & 0.122 & $<0.005$ & $<0010$ & 0.05 & 0.05 \\
$\alpha$-level & 0.05 & 0.05 & 0.05 & 0.05 & 0.05 \\
\hline
\end{tabular}

Table 13. Kruskal-Wallis and Mood's median non-parametric test results for crossing speed on the three crosswalk typologies when participants do not handle their phone.

\begin{tabular}{cccccc}
\hline Test & \multicolumn{1}{c}{ Kruskal-Wallis } & \multicolumn{2}{c}{ Mood's Median } \\
\hline Crossing Typology & Median & Average Rank & Z & Median & Q3-Q1 \\
\hline Standard crosswalk & 1.615 & 59.8 & 4.54 & 1.615 & 0.264 \\
Counter crosswalk & 1.5 & 46.2 & 0.71 & 1.5 & 0.225 \\
Smart light crosswalk & 1.4 & 22 & -5.41 & 1.4 & 0.233 \\
Overall & 1.5 & 43.5 & & Chi-square & 35.57 \\
H & 33.56 & H (adjusted for ties) & 34.08 & P & 0 \\
P & 0 & P (adjusted for ties) & 0 &
\end{tabular}


Table 14. Kruskal-Wallis and Mood's median non-parametric test results for crossing speed on the three crosswalk typologies when participants do handle their phone.

\begin{tabular}{|c|c|c|c|c|c|}
\hline \multirow{2}{*}{$\begin{array}{c}\text { Test } \\
\text { Crossing Typology }\end{array}$} & \multicolumn{3}{|c|}{ Kruskal-Wallis } & \multicolumn{2}{|c|}{ Mood's Median } \\
\hline & Median & Average Rank & $\mathbf{Z}$ & Median & Q3-Q1 \\
\hline Standard crosswalk & 1.518 & 483 & 1.83 & 1.518 & 0.319 \\
\hline Counter crosswalk & 1.5 & 49 & 1.79 & 1.5 & 0 \\
\hline Smart light crosswalk & 1.4 & 27.5 & -3.7 & 1.4 & 0.233 \\
\hline Overall & 1.5 & 42 & & 1.5 & \\
\hline $\mathrm{H}$ & 13.71 & $\mathrm{H}$ (adjusted for ties) & 13.95 & Chi-square & 25.14 \\
\hline $\mathrm{P}$ & 0.001 & $\mathrm{P}$ (adjusted for ties) & 0.001 & $\mathrm{P}$ & 0 \\
\hline
\end{tabular}

\section{Discussion and Conclusions}

The goal of this study was to increase knowledge of the effects of different intersection typologies and smartphone use on pedestrian visual and behavioral performance. Although it plays a central role in the planning and design of pedestrian-vehicle conflict zones, and even in earlier stages would also be beneficial for authorities to improve their regulations about these conflicting areas, little has been performed in the literature on this topic. To address this objective, three signalized intersections were selected that were similar in traffic signal cycle but differed in the overall geometry and typology of the traffic light. Fixations, reaction time, waiting time, crossing time, and crossing speed were calculated for all three intersections, both when participants had their cell phones in hand and when they did not. It was found that at standard crosswalks, the sidewalk and pavement were the most observed elements of the road design, followed by other objects. At crossings where a counter is present, this is the element that attracts the most pedestrian attention, followed by oncoming vehicles at crosswalks. Interestingly, oncoming cars at smart crosswalks are only noticed to a small extent, and the same is true for the road on the right side of the pedestrians, where potentially colliding vehicles could appear. Finally, the red light, although fixed, does not outperform the previously mentioned elements at any of the intersection typologies. These considerations suggest that an appropriate horizontal signalization located in the center of pedestrians' field of view, i.e., in the middle of their path and not on the side, as the smart traffic light, could have better effects on the attention and consequently on the safety of these vulnerable road users. In addition, meters could have a strong impact on pedestrian crossing performance and perceived level of service.

Regarding reaction time, it is noted that reaction time is lower for all crosswalks when walking without a smartphone. This confirms previous findings and is consistent with existing studies. Moreover, the reaction time at smart crosswalks has the highest values both when pedestrians are influenced by the smartphone and when they are not.

The waiting time is different for the three crossing typologies, with the lowest delay for pedestrians at standard crosswalks and the highest at counter crosswalks.

As for the crossing speed, it is higher at the standard crosswalks, both with and without the phone. This could be explained by the duration of the green light for pedestrians: although the studied standard crosswalks are longer than the other two types, the duration of the green light is only $1 \mathrm{~s}$ longer than at the counter crosswalk and smart crosswalk. In addition, people at standard crosswalks do not have meters to indicate how much time they have to cross, and they probably hurry to avoid standing in the middle of the intersection when the light turns red. Nonetheless, it is observed that speed decreases at regular crosswalks when participants handle their phones, while it increases at meters and smart crosswalks.

As expected, the results confirm that the use of a smartphone has a negative impact on pedestrians' attention and their overall performance when crossing the intersection, as their reaction time increases and their behavior becomes less predictable. These two facts have negative implications for pedestrian safety: in fact, longer reaction times mean that 
pedestrians are slower to react to near misses, while the unpredictability of their behavior slows the reactions of motorized road users, who cannot anticipate their next action.

Finally, it cannot be said that the considered smart traffic light really had a positive impact on pedestrians' behavior: in fact, the reaction time at this type of crosswalk was higher in both conditions, and no particular improvements in pedestrians' crossing speed were observed. However, the latter results are related to the observed pedestrian population, which in this study was limited to young adults. To generalize this statement, it would be necessary to expand the sample of participants to include other pedestrian groups characterized by different demographic and personal characteristics that might influence their behavior. Other applications of eye-tracking devices to pedestrian crossing behavior are already being planned. We would like to extend the study to other types of crosswalks, as well as to other pedestrian groups, such as children and the elderly: Understanding the gaze and behavioral characteristics of these even more vulnerable groups of road users can indeed help to identify their needs and improve road infrastructure taking into account their specificities.

Author Contributions: Conceptualization, C.G., I.I.O. and M.Š.; methodology, C.G.; software, C.G.; validation, C.G., I.I.O. and M.Š.; formal analysis, C.G. and I.I.O.; investigation, C.G. and M.Š.; resources, I.I.O. and M.Š.; data curation, C.G.; writing-original draft preparation, C.G.; writingreview and editing, I.I.O. and M.Š.; visualization, C.G.; supervision, I.I.O. and M.Š.; project administration, I.I.O. and M.S. All authors have read and agreed to the published version of the manuscript.

Funding: This research received no external funding.

Institutional Review Board Statement: The study was conducted according to the guidelines of the Declaration of Helsinki and approved by the Ethics Committee of Josip Juraj Strossmayer University of Osijek, Faculty of Civil Engineering and Architecture, dated 05-02-2021 reference number 2158-7718-21-01, issued for the research within the bi-lateral Slovenian-Croatian project "Development of a prediction model of pedestrian children behavior in the urban transport network".

Informed Consent Statement: Informed consent was obtained from all subjects involved in the study.

Data Availability Statement: Data available on request due to privacy restrictions.

Acknowledgments: The authors would like to acknowledge that this research was developed in the framework of the international bi-lateral Slovenian-Croatian project "Development of prediction model of pedestrian children behavior in the urban transport network".

Conflicts of Interest: The authors declare no conflict of interest.

\section{References}

1. European Transport Safety Council (ETSC). How Safe Is Walking and Cycling in Europe? PIN Flash Report 38; ETSC: Brussels, Belgium, 30 January 2020.

2. Alejalil, N.; Davoodi, S. Mobile phone use and its effects on pedestrian distraction. Int. J. High Risk Behav. Addict. 2016, 6, e35431. [CrossRef]

3. Hatfield, J.; Murphy, S. The effects of Mobile phone use on pedestrian crossing behavior at signalized and unsignalized intersections. Accid. Anal. Prev. 2007, 39, 197-205. [CrossRef]

4. Naser, J.L.; Troyer, D. Pedestrian injuries due to mobile phone use in public spaces. Accid. Anal. Prev. 2013, 57, 91-95. [CrossRef]

5. Jiang, K.; Ling, F.; Feng, Z.; Ma, C.; Kumfer, W.; Shao, C.; Wang, K. Effects of mobile phone distraction on pedestrians' crossing behavior and visual attention allocation at a signalized intersection: An outdoor experimental study. Accid. Anal. Prev. 2018, 115, 170-177. [CrossRef] [PubMed]

6. Gruden, C.; Ištoka Otković, I.; Šraml, M. Safety Analysis of young pedestrian behavior at signalized intersections: An eye-tracking study. Sustainability 2021, 13, 4419. [CrossRef]

7. Gilland, J. Driving, Eye-Tracking and Visual Entropy: Exploration of Age and Task Effects. Ph.D. Thesis, University of South Dakota, Vermillion, SD, USA, 2008.

8. Ponds, R.W.H.M.; Brouwer, W.H.; van Wolffellaar, P.C. Age differences in divided attention in a simulated driving task. J. Gerentology 1988, 43, 151-156. [CrossRef]

9. Gao, X.-Y.; Zhang, Y.-F.; Zheng, W.-L.; Lu, B.-L. Evaluating Driving Fatigue detection Algorithms using Eye Tracking Glasses. In Proceedings of the 2015 7th International IEEE/EMBS Conference on Neural Engineering (NER), Montpellier, France, 22-24 April 2015. 
10. Hopstaken, J.F.; van der Linden, D.; Bakker, A.B.; Kompier, M.A.J.; Leung, Y.K. Shifts in Attention During Mental Fatigue: Evidence From Subjective, Behavioral, Physiological, and Eye-tracking Data. J. Exp. Psychol. Hum. Percept. Perform. 2016, 42, 878-889. [CrossRef]

11. Le, A.S.; Suzuki, T.; Aoki, H. Evaluating driver cognitive distraction by eye tracking: From simulator to driving. Transp. Res. Interdiscip. Perspect. 2020, 4, 100087. [CrossRef]

12. Hurtado, S.; Chiasson, S. An Eye-tracking Evaluation of Driver Distraction and Unfamiliar Road signs. In Proceedings of the Automotive 'UI 16: 8th International Conference on Automotive User Interfaces and Interactive Vehicular Applications 2016, Ann Arbor, MI, USA, 24-26 October 2016. [CrossRef]

13. Mantuano, A.; Bernardi, S.; Rupi, F. Cyclist gaze behavior in urban space: AN eye-tracking experiment on the bicycle network of Bologna. Case Stud. Transp. Policy 2017, 5, 408-416. [CrossRef]

14. Kovácsová, N.; Cabrall, C.D.D.; Antonisse, S.J.; de Haan, T.; van Namen, R.; Nooren, J.L.; Schreurs, R.; Hagenzieker, M.P.; de Winter, J.C.F. Cyclists' eye movements and crossing judgments at uncontrolled intersections: An eye-tracking study using animated video clips. Accid. Anal. Prev. 2018, 120, 270-280. [CrossRef]

15. Lévêque, L.; Ranchet, M.; Daniel, J.; Bornard, J.-C.; Bellet, T. Where do pedestrians look when crossing? A state of the art of the eye-tracking studies. IEEE Access 2020, 8, 164833-164842. [CrossRef]

16. Tapiro, H.; Meir, A.; Parmet, Y.; Oron-Gilad, T. Visual search strategies of child-pedestrians in road crossing tasks. In Proceedings of the Human Factors and Ergonomics Society Europe Chapter 2013 Annual Conference; HFES: Washington, DC, USA, 2013.

17. Tapiro, H.; Borowsky, A.; Oron-Gilad, T.; Parmet, Y. Where do older pedestrians glance before deciding to cross a simulated two-lane road? A pedestrian simulator paradigm. In Proceedings of the Human Factors and Ergonomics Society Europe Chapter 2013 Annual Conference; SAGE Publishing: Washington, DC, USA, 2016.

18. Dey, D.; Walker, F.; Martens, M.; Terken, J. Gaze patterns in pedestrian interaction with vehicles: Towards effective design of external human-machine interfaces for automated vehicles. In Proceedings of the AutomotiveUI'19: Proceedings of the 11th International Conference on Automotive User Interfaces and Interactive Vehicular Applications, Utrecht, The Netherlands, 21-25 September 2019.

19. Eisma, Y.B.; van Bergen, S.; ter Brake, S.M.; Hensen, M.T.T.; Tempelaar, W.J.; de Winter, J.C.F. External human-machine interfaces: The effect of display location on crossing intentions and eye movements. Information 2019, 11, 13. [CrossRef]

20. Geruschat, D.R.; Hassan, S.E.; Turano, K.A. Gaze behavior while crossing complex intersections. Optom. Vis. Sci. 2003, 80, 515-528. [CrossRef]

21. Gruden, C.; Ištoka Otković, I.; Šraml, M. Pedestrian Safety at roundabouts: Their crossing and glance behavior in the interaction with vehicular traffic. Accid. Anal. Prev. 2021, 159, 106290. [CrossRef] [PubMed]

22. Fotios, S.; Uttley, J.; Hara, N. Critical pedestrian tasks: Using eye-tracking within a dual task paradigm. In Proceedings of the CIE Centenary Conference "Towards a New Century of Light". CIE Centenary Conference, Paris, France, 15-16 April 2013; pp. 234-240.

23. Fotios, S.; Uttley, J.; Cheal, C.; Hara, N. Using eye-tracking to identify pedestrians' critical visual tasks, Part 1. Dual task approach. Lighting Res. Technol. 2015, 47, 133-148. [CrossRef]

24. Fotios, S.; Uttley, J.; Yang, B. Using eye-tracking to identify pedestrians' critical visual tasks, Part 2. Fixation on pedestrians. Lighting Res. Technol. 2015, 47, 149-160. [CrossRef]

25. Foulsham, T.; Walker, E.; Kingstone, A. The where, what and when of gaze allocation in the lab and the natural environment. Vis. Res. 2011, 51, 1920-1931. [CrossRef]

26. Davoudian, N.; Raynham, P. What do pedestrians look at night? Lighting Res. Technol. 2012, 44, 438-448. [CrossRef]

27. Werneke, J.; Vollrath, M. What does the driver look at? The influence of intersection characteristics on attention allocation and driving behavior. Accid. Anal. Prev. 2012, 45, 610-619. [CrossRef]

28. Li, G.; Wang, Y.; Yhu, F.; Sui, X.; Wang, N.; Qu, X.; Green, P. Drivers' visual scanning behavior at signalized and unsignalized intersections: A naturalistic driving study in China. J. Saf. Res. 2019, 71, 219-229. [CrossRef]

29. Lantieri, C.; Costa, M.; Vignali, V.; Acerra, E.M.; Marchetti, P.; Simone, A. Flashing in-curb LEDs and beacons at unsignalized crosswalks and driver's visual attention to pedestrians during nighttime. Ergonomics 2021, 64, 330-341. [CrossRef] [PubMed]

30. Vignali, V.; Pazzini, M.; Ghasemi, N.; Lantieri, C.; Simone, A.; Dondi, G. The safety and conspicuity of pedestrian crossing at roundabouts: The effect of median refuge island and zebra markings. Transp. Res. Part F 2020, 68, 94-104. [CrossRef]

31. Rosenbloom, T.; Pereg, A. A within-subject design of comparison of waiting time of pedestrians before crossing three successive road crossings. Transp. Res. Part F 2012, 15, 625-634. [CrossRef]

32. Zhu, D.; Sze, N.N.; Feng, Z. The trade-off between safety and time in the red light running behaviours of pedestrians: A random regret minimization approach. Accid. Anal. Prev. 2021, 158, 106214. [CrossRef] [PubMed]

33. Minitab Inc. Minitab Statistical Software, Release 15 for Windows; Minitab Inc.: State College, PA, USA, 2007. 